\title{
COMUNICAÇÃO
}

\section{PRODUÇÃO E DISTRIBUIÇÃO DE FITOMASSA NO GUARANAZEIRO (Paullinia cupana H.B.K. var. sorbilis (Mart.) Ducke)}

\author{
Production and distribution of phytomass in guarana plants
}

\author{
Murilo Rodrigues de Arruda', José Ricardo Escobar², Maria Pinheiro Fernandes Corrêa ${ }^{3}$, \\ Firmino José do Nascimento Filho ${ }^{1}$, Wenceslau Geraldes Teixeira ${ }^{1}$, Adônis Moreira ${ }^{4}$
}

\begin{abstract}
RESUMO
Apesar da importância econômica do guaranazeiro (Paullinia cupana H.B.K. var. sorbilis (Mart.) Ducke) em algumas regiões do Brasil, existem poucas informações sobre sua caracterização fenológica. Assim, realizou-se um estudo cujo objetivo foi de quantificar a produção de fitomassa e sua distribuição, em uma população de guaranazeiros, originadas de propagação sexuada. Foram avaliadas cinco plantas adultas, que lançaram mais de 100 ramos por planta ano ${ }^{-1}$, dos quais apenas $50 \%$ produziram frutos. As plantas lançaram entre 445 e 1294 inflorescências por ano, porém, de $67 \%$ a $98 \%$ produziram apenas um fruto. A produção de matéria seca total foi estimada em $15,8 \mathrm{~kg}$ por planta ao ano, o que corresponde $6350 \mathrm{~kg}$ ha ano ${ }^{-1}$. Nas plantas, o maior acúmulo de matéria seca apresentou a seguinte ordem: folhas>ramos>sementes>ráquis>casca dos frutos+arilo> pecíolos.
\end{abstract}

Termos para indexação: Ramos, folhas, matéria seca total, inflorescências, sementes, Paullinia cupana, guaranazeiro.

\section{ABSTRACT}

The commerce of guarana seeds (Paullinia cupana H.B.K. var. sorbilis (Mart.) Ducke) is economically important in some regions of Brazil. However, few studies are found about its phenological characteristics. The aim of this paper was to study the production and distribution of organic matter in adult plants of guarana. Five individuals, which had more than 100 branches per plant/year, were evaluated. One found out that only $50 \%$ of the branches had fruits. The guarana plants had between 445 and 1294 inflorescences but of these, $67 \%$ to $98 \%$ had only one fruit. The total organic matter was evaluated in $15.8 \mathrm{~kg}$ per plant year ${ }^{-1}$ which means around $6350 \mathrm{~kg}$ ha year ${ }^{-1}$. The organic matter storage in guarana plant had the following sequence: leaves $>$ branches $>$ seeds $>$ rachis $>$ fruit peel+aril> petiole.

Index terms: Branches, total dry matter, seeds, leaves, inflorescences, fruits, guarana, Paullinia cupana.

(Recebido em 22 de novembro de 2006 e aprovado em 27 de novembro de 2007)

O guaranazeiro, Paullinia cupana H.B.K. var. sorbilis (Mart.) Ducke, é uma dicotiledônea, pertencente à família Sapindaceae. Em seu estado natural, cresce como uma liana até atingir o extrato superior da floresta, porém quando cultivada em campo aberto, tem a forma de arbusto subereto com aproximadamente 3,0 metros de altura (CAVALCANTE, 1976). Trata-se de uma espécie monóica, alógama com a polinização feita principalmente por abelhas (GONDIM, 1978). Entretanto, pode ocorrer considerável grau de autofecundação, por apresentar abertura de flores de ambos os sexos em ramos diferentes, numa mesma planta (ESCOBAR et al., 1984a).

As informações sobre o desenvolvimento vegetativo do guaranazeiro são escassas, e segundo Corrêa
(1989), existe a necessidade de caracterização das variações morfológicas, composição química e de produção do guaranazeiro, com estudos mais aprofundados das variações fenotípicas e determinação de descritores qualitativos e quantitativos, para se conhecer melhor a biologia e genética de sua população.

O guaranazeiro é uma espécie perene, de crescimento inicial lento. Em condições de viveiro (EMBRAPA, 1988), a taxa média de emissão foliar em mudas oriundas de pé-franco é de uma folha por mês. No caso de mudas provenientes de estacas, essas possuem em média, aos 6 e 12 meses após o plantio, 11 folhas, 2 ramos e 25 folhas e 6 ramos respectivamente (ESCOBAR, 1986).

\footnotetext{
'Engenheiro Agrônomo, Mestre Fertilidade do Solo e Nutrição de Plantas - Área Técnica -Embrapa Amazônia Ocidental - Rod. AM 010 , Km 30 - Cx. P. 319-69011-970 - Manaus, Amazonas - murilo.arruda@cpaa.embrapa.br

Engenheiro Agrônomo, Doutor Melhoramentos de Plantas - Área Técnica - Embrapa Amazônia Ocidental - ASD de Costa Rica P.O. Box 30-1000 - San Jose, Costa Rica - r.escobar@asd-cr.com

3Pesquisadora Embrapa Caprinos, Caixa Postal D-10, CEP 62011-970, Sobral, CE

${ }^{4}$ Pesquisador Embrapa Pecuária Sudeste, Caixa Postal 13560-970, São Carlos, SP
} 
Aos doze meses após o plantio, as plantas provenientes de estacas apresentam de 3 a 9 ramos por planta com o comprimento variando de 48 a $135 \mathrm{~cm}$, enquanto as mudas de pé-franco apresentam de 2 a 5 ramos, variando de 45 a $61 \mathrm{~cm}$ (EMBRAPA, 1988). Após o plantio no campo, mudas oriundas de pé-franco, passam por uma fase juvenil de crescimento lento, por um período de três a quatros anos (CORRÊA et al., 1984).

Objetivou-se, neste trabalho, quantificar a produção de fitomassa e sua distribuição (folhas, ramos, sementes, ráquis, cascas dos frutos e arilo), em plantas adultas de cinco progênies de guaranazeiro, originadas de propagação sexuada, cultivadas no município de Maués, Amazonas.

O experimento foi conduzido no Campo Experimental de Maués, AM, pertencente a Embrapa Amazônia Ocidental. O clima da região é do tipo Ami, segundo a classificação de Köppen, com temperatura e pluviosidade média anual de $26^{\circ} \mathrm{C}$ e $2.400 \mathrm{~mm}$, respectivamente. $\mathrm{O}$ solo predominante é o Latossolo Amarelo, com pH variando de 4,0 a 4,5, baixa fertilidade natural e textura muito argilosa.

Foram utilizadas cinco progênies adultas de guaranazeiro, sendo quatro das plantas com nove anos de idade e uma com 18 anos, provenientes de campos de seleção de matrizes. As plantas foram adubadas anualmente com $230 \mathrm{~g}$ de uréia $(44 \%$ de N), $200 \mathrm{~g}$ de superfosfato triplo (38\% de $\mathrm{P}_{2} \mathrm{O}_{5}$ ) e $250 \mathrm{~g}$ de sulfato de potássio e magnésio ( $18 \%$ de $\mathrm{K}_{2} \mathrm{O}$ e $4,5 \%$ de $\mathrm{Mg}$ ).

Foram avaliadas as seguintes características: número e comprimento dos ramos lançados, número e comprimento de inflorescências, número de frutos e sementes, número de folhas e peso seco de ramos, ráquis, casca dos frutos + arilo, sementes, folhas e pecíolos.

Depois de coletadas, as amostras foram secas em estufa com ventilação forçada a $75^{\circ} \mathrm{C}$ até peso constante, com exceção das sementes, que foram secas até atingirem $10 \%$ de umidade, valor utilizado na pesquisa e pelo mercado na comercialização das sementes do guaranazeiro.

Para o cálculo da produção de matéria seca das folhas (MSTF) e da matéria seca da ráquis (MSR) foram estabelecidas algumas equações que estão descritas a seguir.

Número e comprimento de ramos: foram contados e medidos todos os ramos, lançados em cada ano e em cada planta nos dois anos de avaliação.

Matéria seca dos ramos: coletaram-se ao acaso e em cada planta, 10 ramos sombreados e 10 ramos não- sombreados, com comprimento médio de $15 \mathrm{~cm}$. A diferenciação entre ramos sombreados e não-sombreados, foi devido à arquitetura da copa, já que alguns ramos se desenvolvem na parte interna da copa, o que poderia afetar o seu crescimento. Determinou-se a quantidade em gramas de matéria seca acumulada, por centímetro de ramo. Com esse fator, foi estimada a quantidade total de matéria seca acumulada anualmente nos ramos, multiplicando o fator obtido pelo comprimento médio e pelo número de ramos por planta.

Número e Comprimento de inflorescências: foram contadas todas as inflorescências lançadas a cada ano e em cada planta nos dois anos de avaliação. Para medida do comprimento médio das inflorescências, selecionou-se ao acaso, 50 inflorescências por planta, por ano.

Número de folhas: estimou-se, primeiramente, o número de folhas por metro de ramo. Para isso, foram coletados e medidos os comprimentos de dez ramos sombreados e dez não-sombreados, por planta. Paralelamente, determinou-se, em cada ramo, o número de folhas. Dessa forma, o número total de folhas lançadas anualmente por planta foi estimado multiplicando-se o fator pelo comprimento de cada ramo e pelo número de ramos. Para se determinar se havia diferenças no número de folhas em ramos sombreados e não-sombreados, realizaram-se análises estatísticas, utilizando-se análise de variância e teste de t ou Tukey, a 5\% de probabilidade, de acordo com metodologia descrita Pimentel-Gomes \& Garcia (2002).

Produção de matéria seca das folhas (MSTF): a matéria seca acumulada nas folhas foi determinada a partir da amostragem de 60 folíolos, coletados ao acaso por planta e secos em estufa a $\pm 75^{\circ} \mathrm{C}$ até peso constante. A matéria seca total acumulada anualmente nas folhas, foi estimada utilizando a seguinte fórmula:

$$
\mathrm{MST}=(\mathrm{MSF} \times 5) \times \mathrm{NTF}
$$

sendo MSF a matéria seca de cada folíolo; cinco é o número de folíolos por folha do guaranazeiro e NTF o número total de folhas produzidas anualmente por uma planta adulta;

Matéria seca dos pecíolos: foram coletados, ao acaso, 10 pecíolos por planta. Após secos em estufa, até peso constante, mediu-se a produção de matéria seca por pecíolo. Os dados foram utilizados para se estimar a matéria seca total acumulada nos pecíolos por ano e por planta, multiplicando-o pelo total de folhas.

Matéria seca da ráquis (MSR): foram avaliadas 30 ráquis coletadas ao acaso por planta, e determinou-se a 
matéria seca, em gramas, por centímetro de ráquis. A estimativa da matéria seca total da ráquis por planta por ano foi obtida pela seguinte fórmula:

$$
\text { MSR }=(\text { MSCR } \times \text { CMI }) \times \text { NTIP }
$$

onde MSCR é matéria seca, em gramas, por centímetro de ráquis; $\mathrm{CMI}$ o comprimento médio da inflorescência e NTIP o número total de inflorescências por planta.

Matéria seca de sementes: avaliaram-se 50 sementes por planta. A matéria seca obtida, foi multiplicada pelo número total de sementes por planta;

Matéria seca da casca dos frutos e do arilo: coletaram-se ao acaso 50 frutos por planta, que foram secos em estufa até peso constante. A matéria seca do fruto foi subtraída do peso das sementes e multiplicada pelo total de frutos por planta, obtendo-se a matéria seca da casca dos frutos e do arilo por planta.

Número total de ramos, número de ramos produtivos e comprimento de ramos: o número de ramos lançados e produtivos por planta nos dois anos de avaliação, está na Tabela 1 . Observou-se que o número total de ramos variou de 102 na planta 3, a 244 na planta 4, no primeiro e segundo ano de avaliação, respectivamente. Percebe-se ainda, que, em média, menos de $50 \%$ dos ramos são produtivos, ou seja, apresentaram ao menos um fruto, significando que existe uma grande proporção de ramos demandando nutrientes e energia para seu crescimento sem, no entanto, haver produção de frutos.

No campo, observa-se que parte desse problema se explica pelo ataque do tripes (Liothrip adisi STRASSSEN, 1977), que provoca intensa perda de flores, quando o inseto não é controlado adequadamente e/ou pela não-polinização pelas abelhas, pois de acordo com Escobar et al. (1984b), as flores do guaranazeiro permanecem abertas e viáveis por apenas algumas horas, durante períodos da madrugada e parte das manhãs.

A freqüência de distribuição do comprimento dos ramos é apresentada na Figura 1. Verificou-se que 78,9\% dos ramos possuíam menos de $50 \mathrm{~cm}$ de comprimento enquanto aqueles com mais de $100 \mathrm{~cm}$ representaram 11 $\%$ do total. Sabe-se que a frutificação do guaranazeiro ocorre nos ramos do ano, portanto, é importante se conhecer a quantidade e o comprimento dos ramos lançados, e sua relação com a produção de frutos. Em plantas oriundas de mudas clonadas, nota-se que não existe uma relação entre produção de frutos e comprimento de ramos, pois plantas geneticamente selecionadas, classificadas como de ramos longos (ATROCH, 2001), e que apresentam um maior volume de copa, produzem tanto quanto plantas de ramos curtos, com menor volume de copa.

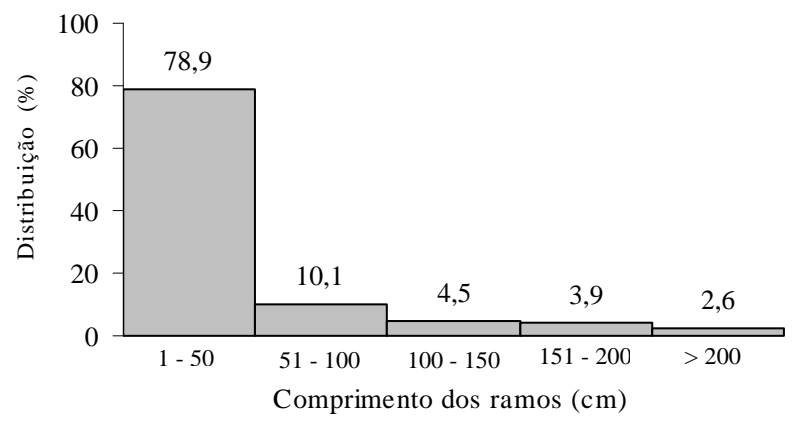

Figura 1 - Distribuição do comprimento de ramos, em cinco plantas adultas de guaranazeiro, avaliadas por dois anos consecutivos.

Tabela 1 - Número total de ramos lançados e número de ramos com frutos por planta $a^{-1}$.

\begin{tabular}{|c|c|c|c|c|c|c|}
\hline \multirow[t]{3}{*}{ Planta* } & \multicolumn{2}{|c|}{ Ramos lançados } & \multicolumn{4}{|c|}{ Ramos com frutos } \\
\hline & \multicolumn{2}{|c|}{ Total } & \multicolumn{2}{|c|}{ Total } & \multicolumn{2}{|c|}{$\%$} \\
\hline & Ano 1 & Ano 2 & Ano 1 & Ano 2 & Ano 1 & Ano 2 \\
\hline 1 & 161 & 140 & 81 & 54 & 50,3 & 38,6 \\
\hline 2 & 122 & 173 & 50 & 41 & 40,9 & 23,7 \\
\hline 3 & 102 & 169 & 50 & 84 & 49,0 & 49,7 \\
\hline 4 & 170 & 244 & 84 & 81 & 49,4 & 33,2 \\
\hline 5 & 177 & 135 & 106 & 68 & 59,9 & 50,3 \\
\hline Média & 146 & 172 & 74 & 66 & 49,9 & 39,1 \\
\hline
\end{tabular}

\footnotetext{
* Planta 1: 18 anos de idade; plantas 2, 3, 4, e 5, 9 anos de idade
} 
Assim, o número de ramos e o número de inflorescências por ramo, parecem estar mais correlacionados com a produção do que o comprimento do ramo.

Comprimento; número de inflorescências; número de frutos e sementes: em média, o comprimento das 500 inflorescências medidas nos dois anos de avaliação foi de 20,4 cm. Corrêa (1989) observou que o comprimento das inflorescências variou de 4,0 a 57,8 cm, em plantas originadas de pés francos e de estacas, essas últimas com média de $20,8 \mathrm{~cm}$.

Pela Tabela 2, verifica-se que, em média, cada planta lançou 640 e 951 inflorescências no primeiro e segundo ano de avaliação, respectivamente, com uma amplitude de 445 a 1294. No primeiro ano, $85 \%$ das inflorescências produziram ao menos um fruto e no segundo ano, $69 \%$, dentro de uma variação de 47 a $98 \%$, dependendo da planta e do ano.

Verificou-se também, que $76 \%$ dos ramos, apresentaram entre uma e dez inflorescências e apenas $2 \%$ produziram mais de 20 (Figura 2). No geral, o guaranazeiro produz 796 inflorescências ao ano, das quais 586 produzem sementes.

O número médio de frutos e sementes por inflorescência foi de 6 e 8 no primeiro ano de avaliação e 4 e 5, no segundo ano. Corrêa (1989), encontrou uma variação de 7 a 172 frutos por inflorescência, com média de 38,9 frutos por inflorescência. Valois et al. (1979) encontraram em média, 5,10 frutos por inflorescência, indicando uma alta variabilidade nesse caráter.

A Figura 3 representa a distribuição da freqüência do número de frutos por ramo, em que $74 \%$ dos ramos produziram de 1 a 50 frutos. A produção acima de 150 frutos ocorreu em menores porcentagens, representando apenas $4 \%$ do total de ramos lançados.

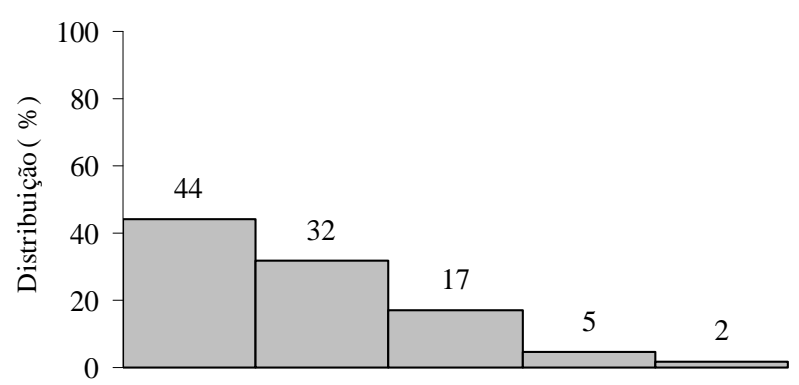

Número de inflorescências

Figura 2 - Distribuição do número de inflorescências por ramo, em cinco plantas adultas de guaranazeiro, avaliadas por dois anos consecutivos.

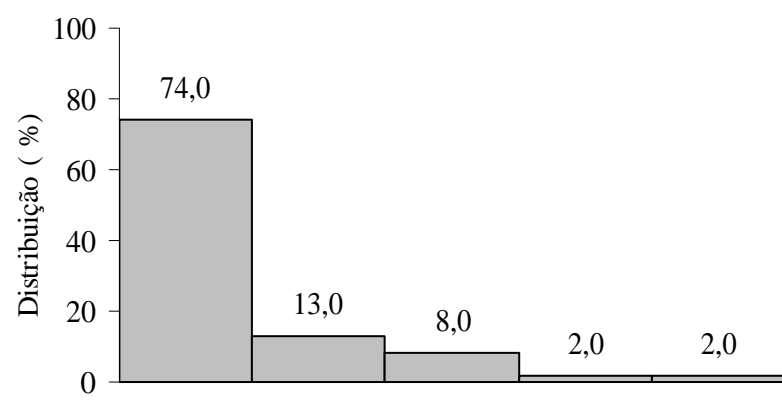

Número de frutos

Figura 3 - Distribuição do número de frutos por ramo, em cinco plantas adultas de guaranazeiro, avaliadas por dois anos consecutivos.

Número de folhas: na Tabela 3, estão os dados coletados sobre o número de folhas, por metro de ramo. Em média, cada metro de ramo, apresentou 7,8 folhas compostas. Estatisticamente, não houve diferença significativa, pelo teste de Tukey, a 5\% de probabilidade, no número de folhas em ramos externos à copa, ou seja, não-sombreados e aqueles localizados no interior da planta.

Tabela 2 - Número total de inflorescências e número de inflorescências produtivas, por planta por ano.

\begin{tabular}{|c|c|c|c|c|c|c|}
\hline \multirow[b]{3}{*}{ Planta* } & & & \multicolumn{4}{|c|}{ Inflorescências produtivas } \\
\hline & \multicolumn{2}{|c|}{ Lançadas } & \multicolumn{2}{|c|}{ Total } & \multicolumn{2}{|c|}{$\%$} \\
\hline & Ano 1 & Ano 2 & Ano 1 & Ano 2 & Ano 1 & Ano 2 \\
\hline 1 & 984 & 1.059 & 655 & 498 & 67 & 47 \\
\hline 2 & 551 & 756 & 454 & 461 & 82 & 61 \\
\hline 3 & 445 & 1.294 & 434 & 903 & 98 & 70 \\
\hline 4 & 660 & 771 & 607 & 650 & 92 & 84 \\
\hline 5 & 560 & 876 & 487 & 713 & 87 & 81 \\
\hline dia & 640 & 951 & 527 & 645 & 85 & 69 \\
\hline
\end{tabular}

* Planta 1: 18 anos de idade; plantas 2, 3, 4, e 5, 9 anos de idade. 
Tabela 3 - Número de folhas por metro de ramo de plantas adultas do guaranazeiro ${ }^{1}$.

\begin{tabular}{cccc}
\hline Planta* $^{*}$ & $\begin{array}{c}\text { Não- } \\
\text { sombreados }\end{array}$ & Sombreados & Média \\
\hline 1 & 6,5 & 7,1 & 6,8 \\
2 & 7,1 & 8,2 & 7,6 \\
3 & 9,5 & 7,9 & 8,7 \\
4 & 7,8 & 7,3 & 7,5 \\
5 & 8,0 & 8,2 & 8,1 \\
\hline Média & $7,8 \mathrm{a}$ & $7,7 \mathrm{a}$ & 7,8
\end{tabular}

Letras iguais na mesma linha, indicam não haver diferença estatística significativa pelo teste de Tukey, a 5\% de probabilidade.

** Planta 1: 18 anos de idade; plantas 2, 3, 4, e :, 9 anos de idade.

Produção de matéria seca: pelo teste de t, a 5\% de probabilidade, houve diferenças estatísticas para a produção de matéria seca dos ramos, pecíolos, folhas, ráquis, sementes e casca dos frutos. No geral, a planta 5, com nove anos de idade, apresentou a maior produção de massa seca e de sementes, dentro de cada ano. Nota-se também que houve pouca influência entre os anos na produção da matéria seca dentro de uma planta, com exceção da produção de sementes. As plantas 1 e 4 mostraram uma queda de mais de $50 \%$ na produção de sementes, enquanto nas plantas 2 e 5 , houve acréscimo. É mais provável que essas diferenças tenham ocorrido em função de falhas na polinização e incidência do tripes. Os dados da Tabela 4 confirmam o que foi verificado no campo, que é uma elevada variabilidade na morfologia do guaranazeiro, como ângulo de inserção e comprimento dos ramos, folhas e inflorescências, hábito de crescimento prostrado ou ereto, apresentados em plantas de pés-francos.
Levando em consideração o estande de plantio atualmente recomendado para o guaranazeiro (PEREIRA,

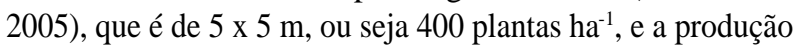
média de matéria seca das cinco plantas nos dois anos avaliados, chega-se a um total de $6.350 \mathrm{~kg} \mathrm{ha}^{1}$ ao ano de matéria seca, sendo $1780 \mathrm{~kg}$ exportados via ráquis, sementes e cascas.

Na Figura 4 observa-se a distribuição de matéria seca no guaranazeiro. As folhas foram responsáveis por $45,3 \%$ da matéria seca total, seguida dos ramos, $23,5 \%$, e sementes, $12,7 \%$. Levando-se em consideração que ráquis, cascas e sementes são colhidas, verifica-se que $28,1 \%$ da matéria seca produzida pode ser exportada do plantio. Isso indica que o guaranazeiro recicla a maior parte da matéria seca que produz através principalmente das folhas, que são trocadas anualmente. Caso as cascas e ráquis sejam devolvidas ao plantio, a exportação de massa seca e nutrientes via sementes, representa apenas $12,7 \%$ do total produzido.

É importante levar esses dados em consideração em ensaios de adubação do guaranazeiro, em especial nas plantas adultas, pois essa capacidade de ciclagem de matéria seca, aliada à pequena exportação, em termos de peso seco, representadas pelas sementes, pode diminuir a quantidade de fertilizantes a ser utilizada na cultura.

O guaranazeiro produz $6.350 \mathrm{~kg} \mathrm{ha}^{-1}$ ao ano de matéria seca, sendo que $1780 \mathrm{~kg}$ são exportados via ráquis, sementes e cascas.

Em média, o guaranazeiro proveniente de sementes, lança 159 ramos por planta a cada ano, dos quais 46 produzem frutos.

O guaranazeiro, com idade das plantas entre 9 e 18 anos, emite, em média, 796 inflorescências, com 20,5 cm de

Tabela 4 - Matéria seca total em diferentes partes do guaranazeiro.

\begin{tabular}{|c|c|c|c|c|c|c|c|c|c|c|c|c|}
\hline \multirow{3}{*}{ Componente } & \multicolumn{12}{|c|}{ Planta* } \\
\hline & \multicolumn{2}{|c|}{1} & \multicolumn{2}{|c|}{2} & \multicolumn{2}{|c|}{3} & \multicolumn{2}{|c|}{4} & \multicolumn{2}{|c|}{5} & \multirow{2}{*}{ média } & \multirow{2}{*}{ L.C. ${ }^{1}$} \\
\hline & ano1 & Ano2 & Ano1 & ano 2 & ano1 & ano 2 & ano 1 & Ano2 & ano1 & Ano2 & & \\
\hline \multicolumn{13}{|c|}{$\mathrm{kg} \mathrm{planta}^{-1} \mathrm{ano}^{-1}$} \\
\hline Ramos & 3,3 & 2,6 & 2,5 & 2,4 & 4,4 & 3,8 & 3,7 & 4,7 & 4,5 & 5,5 & 3,74 & 0,79 \\
\hline Pecíolos & 0,4 & 0,3 & 0,3 & 0,3 & 0,6 & 0,5 & 0,5 & 0,7 & 0,6 & 0,7 & 0,49 & 0,12 \\
\hline Folhas & 6,3 & 4,9 & 4,7 & 4,5 & 8,5 & 7,3 & 7,1 & 9,1 & 8,7 & 10,7 & 7,18 & 1,58 \\
\hline Ráquis & 1,4 & 1,4 & 1,2 & 1,4 & 1,0 & 2,1 & 1,3 & 1,1 & 1,0 & 1,3 & 1,32 & 0,24 \\
\hline Sementes & 0,8 & 0,3 & 2,5 & 3,0 & 1,6 & 1,4 & 3,2 & 1,4 & 2,6 & 3,3 & 2,01 & 0,79 \\
\hline Casca frutos & 0,7 & 0,3 & 1,1 & 0,9 & 1,2 & 1,0 & 2,3 & 0,9 & 1,3 & 1,4 & 1,11 & 0,39 \\
\hline Total & 12,9 & 9,8 & 12,3 & 12,5 & 17,3 & 16,1 & 18,1 & 17,9 & 18,7 & 22,9 & 15,85 & 2,95 \\
\hline
\end{tabular}

1. Limites de confiança pelo teste $\mathrm{t}$, a $5 \%$ de probabilidade

* Planta 1: 18 anos de idade; plantas 2, 3, 4, e 5, 9 anos de idade. 


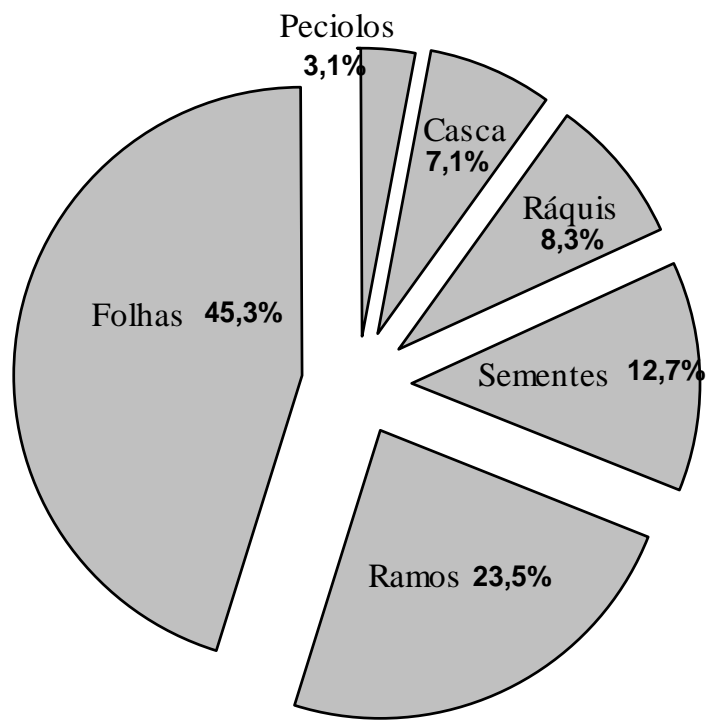

Figura 4 - Distribuição da matéria seca do guaranazeiro, em plantas originadas de pés-francos.

comprimento, com a presença de, pelo menos, um fruto em 586, o que representa $77 \%$ do total, nas condições edafoclimáticas do município de Maués, Amazonas.

\section{AGRADECIMENTOS}

À Rivaldo Gonçalves de Araújo.

\section{REFERÊNCIAS BIBLIOGRÁFICAS}

ATROCH, A. L. Principais resultados de pesquisa com a avaliação de clones de guaranazeiro no período de 1985 a 1994. In: REUNIÃO TÉCNICA DA CULTURA DO GUARANÁ, 1., 2000, Manaus. Resumos... Manaus: Embrapa Amazônia Ocidental, 2001. p. 26-27. (Documentos, 16).

CAVALCANTE, P. B. Frutas comestíveis da Amazônia. Manaus: INPA, 1976. 166 p.

CORREA, M. P. F. Caracteres quantitativos e qualitativos para a descrição morfológica do guaraná (Paullinia cupana var. sorbilis (Mart.) Ducke). 1989. 186 f. Tese (Doutorado) - Instituto Nacional de Pesquisas da Amazônia/Fundação Universidade do Amazonas, Manaus, 1989.
CORREA, M. P. F.; ESCOBAR, J. R.; FONSECA, C. E. L. Propagação vegetativa do guaranazeiro (Paullinia cupana var. sorbilis (Mart.) Duke) alguns resultados de pesquisa. In: SIMPÓSIO BRASILEIRO DO GUARANÁ, 1., 1983, Manaus. Anais... Manaus: Embrapa-UEPAE, 1984. p. 204-219.

EMPRESA BRASILEIRA DE PESQUISA AGROPECUÁRIA. Curso sobre aspectos gerais da cultura do guaraná. Manaus: UEPAE, 1988. 149 p.

ESCOBAR, J. R. Herdabilidade de alguns caracteres da fase juvenil de clones de guaraná (Paullinia cupana var. sorbilis). Manaus: Embrapa-UEPAE, 1986. 23 p. (Boletim de Pesquisa, 6).

ESCOBAR, J. R.; CORRÊA, M. P. F.; AGUILERA, F. P. Estruturas florais, floração e técnicas para a polinização controlada do guaranazeiro. Pesquisa Agropecuária Brasileira, Brasília, v. 29, n. 5, p. 615-622, 1984a.

ESCOBAR, J. R.; CORRÊA, M. P. F.; BARRETO, J. F. Desenvolvimento e crescimento de mudas de guaraná. Pesquisa Agropecuária Brasileira, Brasília, v. 21, n. 4, p. 399-408, 1984b.

GONDIM, C. J. E. Alguns aspectos da biologia reprodutiva do guaraná. 1978. 83 f. Dissertação (Mestrado) - Instituto Nacional de Pesquisas da Amazônia/Fundação Universidade do Amazonas, Manaus, 1978.

\section{PEREIRA, J. C. R. Cultura do guaranazeiro no} Amazonas. 4. ed. Manaus: Embrapa Amazônia Ocidental, 2005. 40 p. (Sistemas de produção, 2).

PIMENTEL-GOMES, F.; GARCIA, C. H. Estatística aplicada a experimentos agronômicos e florestais: exposição com exemplos e orientações para uso de aplicativos. Piracicaba: FEALQ, 2002. 309 p.

VALOIS, A. C. C.; CORRÊA, M. P. F.; VASCONCESLOS, M. E. C. de. Estudos de caracteres correlacionados com a produção de amêndoa seca no guaranazeiro. Pesquisa Agropecuária Brasileira, Brasília, v. 14, n. 2, p. 175-179, 1979. 